\title{
INDICADORES FÍSICO-QUÍMICOS E MICROBIOLÓGICOS DA QUALIDADE DO SOLO UTILIZADO PARA VITICULTURA EM SANTA TERESA, ESPÍRITO SANTO
}

\author{
Breno Barcellos Campos ${ }^{1,3}$, Giana Possati de Moraes $^{2}$, Gisele Dantas Gomes ${ }^{3}$, Nicole Amaral Batista ${ }^{3}$
}

\begin{abstract}
RESUMO - A viticultura vem se expandindo na região serrana do estado do Espírito Santo e o aumento da produção e melhoria da qualidade dos frutos são as principais metas do governo e dos pequenos produtores da região. Dentre as variáveis que influenciam no cultivo de qualquer fruta, conhecer as propriedades do solo é de extrema importância para o sucesso da cultura. Sendo assim, o presente trabalho buscou analisar as propriedades físico-químicas e microbiológicas do solo de culturas das uvas BRS Cora e Niágara Rosada (Vitis labrusca) de um micro produtor do município de Santa Teresa, Espírito Santo. Para isso, determinou-se a textura e o pH do solo, as concentrações de matéria orgânica, macro e micronutrientes disponíveis no solo, todos essenciais para as videiras. Classificados como arenosos, os solos das cultivares BRS Cora e Niágara Rosada apresentaram acidez média e elevada respectivamente, e baixas concentrações de fósforo, cálcio e magnésio. Os demais elementos apresentaram-se de forma diferenciada em ambas as áreas de plantio. Concluímos com este trabalho que a caracterização do solo sugere a necessidade de correção e manejo adequados para a cultura, além do desenvolvimento sustentável da mesma.
\end{abstract}

Palavras chave: fertilização, macronutrientes, micronutrientes, Vitis labrusca.

\section{PHYSICAL-CHEMICAL AND MICROBIOLOGICAL INDICATORS OF THE SOIL QUALITY USED FOR VITICULTURE IN SANTA TERESA, ESPÍRITO SANTO}

\begin{abstract}
Viticulture has been expanding in the mountainous region of the state of Espírito Santo and increasing production and improving quality are the main goals of the government and small producers in the region. Among the variables that influence the cultivation of any fruit, know the soil properties is extremely important for the success of the culture. Therefore, this study aimed to analyze the physicochemical and microbiological properties in the soil where grapes BRS Cora and Niágara Rosada (Vitis labrusca) are growing, in the city of Santa Teresa, Espírito Santo. For this, it was determined the texture and the soil pH, the concentrations of organic matter, macro and micronutrients available in the soil, wich are essential factors for the vines. Classified as sandy, soils BRS Cora and Niágara Rosada showed medium and high acidity, respectively, and low concentrations of phosphorus, calcium and magnesium. The other elements were present in different amounts in both planting areas. We conclude with this work that the characterization of the soil suggests the requirement of correction and management appropriate to the culture, in addition to its sustainable development.
\end{abstract}

Keywords: fertilization, macronutrients, micronutrients, Vitis labrusca.

\footnotetext{
${ }^{1}$ Mestre em Microbiologia Agrícola pela UFV e professor na SEDU/ES. brenobcampos @ hotmail.com.

${ }^{2}$ Bacharel em Engenharia Química - UVV.

${ }^{3}$ Bacharel e licenciado em Química - FAESA.
} 


\section{INTRODUÇÃO}

A videira, de nome científico Vitis labrusca, vem sendo cultivada no Brasil e esta atividade possui grande importância econômica. A atual produção nacional de uvas vem crescendo com uma estimativa de $24 \%$ para 2017, em relação à safra de 2016. Caracteriza-se por uma atividade desenvolvida principalmente em pequenas propriedades rurais com uso de mão-de-obra familiar, nas regiões Sul e Sudeste do país. Diferente do que ocorre na região Nordeste, onde prevalecem grandes empresas rurais, mas para ambos, há o interesse na produção de uvas de mesa, vinhos e sucos (Corrêa, 1984; Roberto et al., 2004; Souza et al., 2014; IBGE, 2017).

O solo é um dos principais elementos no processo de produção dos frutos, pois é a base de sustentação e desenvolvimento das plantas, tornando-se de grande influência sobre a qualidade das uvas e, consequentemente, dos seus derivados. Algumas características do solo são variáveis, como o pH e a disponibilidade de nutrientes (macro e micronutrientes), que influenciam diretamente em características das uvas, como sabor, acidez, teor de açúcares, coloração, resistência da casca, formato dos cachos, dentre outras. Desta maneira, torna-se essencial atender as necessidades fisiológicas das videiras para obter uma produção satisfatória (Reganold et al., 2001; Luchese et al., 2002; Wutke et al., 2004, Chavarria et al., 2011; Padmavathy \& Poyyamoli, 2011; Miele et al., 2014).

Levando em consideração a ascensão do desenvolvimento agrícola do Estado do Espírito Santo, bem como o interesse de investimentos em vitivinicultura por parte dos agricultores da região (SEAG, 2008; Camargo et al., 2011), o presente estudo teve por objetivo analisar as características físico-químicas e microbiológicas do solo de um micro produtor de uvas BRS Cora e Niágara Rosada, no município de Santa Teresa/ES.

\section{MATERIAL E MÉTODOS}

Localizado no Estado do Espírito Santo, Santa Teresa possui uma área total de $671,94 \mathrm{~km}^{2}$, com uma sede urbana e muitos distritos. O sítio Boa Vista está situado no distrito Tabocas (1955'05' S, 4041'35" W), a $12 \mathrm{~km}$ da sede do município. Possui uma área de três hectares contendo 3000 videiras em produção, das variedades BRS Cora, Niágara Rosada, Isabel e IAC 138-22. São realizadas podas programadas que possibilitam duas colheitas ao ano, nos meses de maio e dezembro. Antes da realização da poda, são aplicados adubo orgânico e calcário na área plantada, após esse processo não é feito nenhum tratamento no solo até a colheita. As cultivares estão instaladas em terrenos com planos diferenciados, estando a cultivar BRS Cora sob área de plantio plana e a Niágara em uma área de plantio inclinada.

As coletas de solo foram realizadas em agosto de 2010 , temperatura de $20^{\circ} \mathrm{C}$. Para a realização da coleta das amostras de solo das cultivares de maior produtividade, BRS Cora e Niágara Rosada, foram selecionados 12 pontos em cada área plantada, traçandose um percurso em forma de zigue-zague (Lemos, 2002) de maneira a abranger toda a extensão dos terrenos. A cultivar BRS Cora estava sob recente adubação enquanto a Niágara, com calagem recente ( 3 dias). Foram coletados aproximadamente $500 \mathrm{~g}$ de solo de cada ponto, nas profundidades de $0 \mathrm{~cm}$ a $20 \mathrm{~cm}$ e de $20 \mathrm{~cm}$ a 40 $\mathrm{cm}$, sendo armazenados em sacos plásticos individuais. Para as análises microbiológicas foram utilizados sacos plásticos estéreis. As amostras foram analisadas conforme o fluxograma ilustrado na Figura 1.

A análise granulométrica foi iniciada com a pesagem de uma fração do solo da BRS Cora e do solo da Niágara

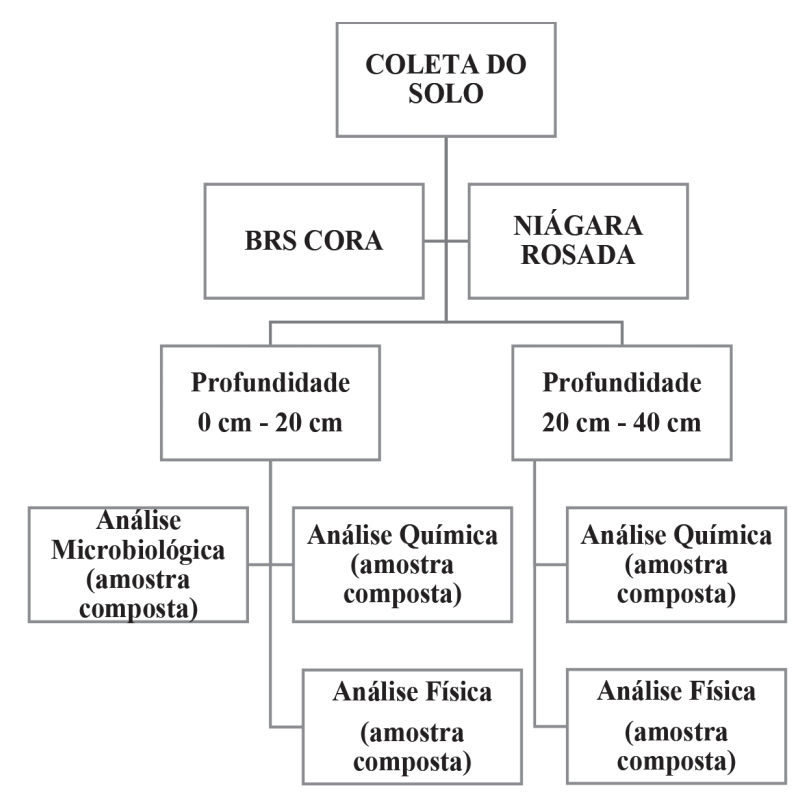

Figura 1 - Fluxograma de coleta e distribuição das amostras para análise de solo. 
Rosada, que em seguida foram submetidas a secagem. Após este procedimento, as partículas do solo foram desagradas e as amostras levadas para um conjunto de 5 peneiras com malhas de $2.000 \mathrm{~mm}, 1.000 \mathrm{~mm}, 500$ $\mathrm{mm}, 150 \mathrm{~mm}$ e $053 \mathrm{~mm}$, seguido de agitação constante até a completa separação das frações. Após este procedimento foi realizada a pesagem do total de partículas dos solos (Tabela 1) retidas em cada uma delas (Lemos, 2002).

O teor de matéria orgânica do solo (MOS) foi determinado pelo método colorimétrico de oxidação de MOS por dicromato de sódio, adaptado a partir do método Walkley-Black, usando-se dicromato de sódio $\left(\mathrm{Na}_{2} \mathrm{Cr}_{2} \mathrm{O}_{7}\right) 4 \mathrm{~mol} \mathrm{~L}^{-1}$ e ácido sulfúrico $\left(\mathrm{H}_{2} \mathrm{SO}_{4}\right) 10 \mathrm{~mol}$ $\mathrm{L}^{-1}$ (Pavan et al., 1992; Tecchio et al., 2006). Para a quantificação dos teores de MOS, foi utilizado o espectrofotômetro UV-Vis (Micronal, B542) em comprimento de onda de $650 \mathrm{~nm}$. $\mathrm{O} \mathrm{pH}$ foi determinado misturando-se $10 \mathrm{~g}$ de TFSA (terra fina seca ao ar) em $25 \mathrm{~mL}$ de água destilada. Com a obtenção desse extrato, foi utilizado um potenciômetro devidamente calibrado, que forneceu os valores de $\mathrm{pH}$ (Camargo et al., 2009).

A extração de fósforo e de potássio no solo foi realizada através do extrator Mehlich-1 (ácido sulfúrico $0,0125 \mathrm{~mol} \mathrm{~L}^{-1}$ e ácido clorídrico $0,05 \mathrm{~mol} \mathrm{~L}^{-1}$ ); para a extração do enxofre foi utilizada uma solução de dihidrogenofosfato de cálcio $\left(\mathrm{Ca}\left(\mathrm{H}_{2} \mathrm{PO}_{4}\right)_{2}\right) 0,01 \mathrm{~mol} \mathrm{~L}^{-}$ 1. O fósforo e enxofre foram quantificados por espectrofotometria UV-Vis e potássio por fotometria de chama (Micronal, B462) (Tomé, 1997; Valladares et al., 2001; Osório Filho et al. 2007; Bortolon et al, 2010). Os Teores de Nitrogênio Total foram estimados pela multiplicação do teor de matéria orgânica por 0,05 ,

Tabela 1 - Frações de solo das cultivares BRS Cora e Niágara Rosada retidas em cada malha

\begin{tabular}{cccccc}
\hline \multirow{2}{*}{$\begin{array}{c}\text { Malha } \\
(\mathrm{mm})\end{array}$} & \multicolumn{2}{c}{$\begin{array}{c}\text { BRS } \\
\text { Cora }\end{array}$} & & \multicolumn{2}{c}{$\begin{array}{c}\text { Niágara } \\
\text { Rosada }\end{array}$} \\
\cline { 2 - 3 } \cline { 5 - 6 } & $(\mathrm{g})$ & $(\%)$ & & $(\mathrm{g})$ & $(\%)$ \\
\hline 2.000 & 20,26 & 12,84 & & 19,60 & 13,28 \\
1.000 & 27,75 & 17,59 & & 25,74 & 17,44 \\
500 & 52,70 & 33,40 & & 35,70 & 24,20 \\
150 & 39,00 & 24,72 & & 53,80 & 36,46 \\
053 & 10,78 & 6,83 & & 5,55 & 3,76 \\
$<053$ & 7,29 & 4,62 & & 7,16 & 4,85 \\
Total & 157,78 & 100,00 & & 147,55 & 100,00 \\
\hline
\end{tabular}

considerando-se que esta contém cerca de $5 \%$ de nitrogênio, conforme descrito por Tomé (1997). Para se determinar as concentrações de Cálcio, Magnésio, Cobre, Ferro, Manganês e Zinco foi realizada uma extração com cloreto de potássio $1 \mathrm{~mol} \mathrm{~L}^{-1}$. A quantificação desses elementos foi determinada por espectrofotometria de absorção atômica (Buck Scientific, 210 VG). Para extração do Boro foi utilizado o método da água quente $\left(\mathrm{BaCl}_{2} 1,25 \mathrm{~g} \mathrm{~L}^{-1}\right.$, na relação 1:2) e quantificado por espectrofotometria UV-Vis (Tomé, 1997; Raij et al., 2001; Valladares et al., 2001; Skoog et al., 2002).

Para a análise de micro-organismos do solo foi adotada a técnica de inoculação pour plate nos meios de cultura seletivos, Ágar Solo, Ágar Martim e Ágar Amido, para o crescimento de bactérias, fungos e actinomicetos, respectivamente. A partir de $1 \mathrm{~g}$ do solo foi promovida a diluição seriada da amostra devidamente homogeneizada, inoculando-se $1000 \mu \mathrm{L}$ das diluições $10^{-3}, 10^{-4} \mathrm{e} 10^{-5}$ aos meios de cultura ainda líquidos contido nas placas de Petri, homogeneizando-se. Em seguida, as placas de Ágar Solo e Ágar Amido foram incubadas a uma temperatura de $\pm 35^{\circ} \mathrm{C}$ por $48 \mathrm{~h}$ e as placas de Ágar Martim permaneceram em temperatura ambiente $\left(25\right.$ a $30^{\circ} \mathrm{C}$ ) por $72 \mathrm{~h}$ (Silva et al., 2001; Macêdo, 2003; Souto et al., 2008). O experimento foi realizado em triplicata. Os resultados foram expressos em unidades formadoras de colônias (UFC g ${ }^{-1}$ ) por grama de solo, selecionandose as diluições com números entre 30 e 300 UFC (Barroti \& Nahas, 2000; Moreira \& Siqueira, 2002; Padmavathy \& Poyyamoli, 2011).

\section{RESULTADOS E DISCUSSÃO}

Foi adotada por referência a relação grama/ porcentagem para cada amostra, a maior porcentagem dos solos, das duas cultivares, foi constituída por partículas nas frações de areias (> $80 \%$ ). De acordo com o Triângulo de Classes Texturais do Solo (Camargo et al., 2009), esses valores correspondem às propriedades de um solo arenoso, de caráter ácido e confirmado pela análise do $\mathrm{pH}$ (Tabela 2). Os resultados indicam acidez média $(5,1$ a 6 ) para o solo da cultivar BRS Cora e acidez elevada $(\leq 5,0)$ para o solo da cultivar Niágara Rosada, o que também é comum em solos das regiões tropicais e subtropicais (Rodrighero et al., 2015). Solos arenosos devem receber frequente fertilização e uma irrigação adequada para a obtenção de uma boa produção. A disponibilidade de nutrientes e de MOS pode se tornar limitante em solos ácidos, a adição de matéria orgânica 
pode melhorar a capacidade de retenção da umidade e dos nutrientes das plantas (Bertoni \& Lombardi Neto, 1999; Rossi et al., 2015). Miele et al (2014), relatam a importância das características de solos da região do Vale dos Vinhedos - RS, nas propriedades físicoquímicas das uvas cultivadas nesses solos.

De acordo com os dados apresentados anteriormente, o solo analisado encontra-se dentro dos padrões para MOS, entre 1,6 a 3,0 dag $\mathrm{dm}^{-3}$. A MOS influencia em algumas propriedades químicas, físicas, físico-químicas e biológicas do solo, interferindo em processos como a correção e fertilidade, controle do pH devido ao efeito tampão, aumento da capacidade de retenção de água e o favorecimento do crescimento de microrganismos (Luchese et al., 2002; Sampaio et al., 2012).

Quanto aos nutrientes do solo, os resultados apresentados nas Tabelas 2 e 3, mostram as concentrações dos macronutrientes e micronutrientes, respectivamente, encontrados nas amostras de solo. Os teores de fósforo, cálcio e magnésio, indicam que suas concentrações se encontram baixas para ambas as cultivares $(<20$ $\mathrm{mg} \mathrm{dm}^{-3},<1,5 \mathrm{~mol} \mathrm{dm}^{-3} \mathrm{e}<0,6 \mathrm{~mol} \mathrm{dm}^{-3}$, respectivamente). As baixas concentrações de fósforo e de cálcio podem estar relacionadas com o pH ligeiramente ácido de solo, devendo estar acima de 5,5 para que esse nutriente permaneça disponível. Os valores de magnésio estão associados aos de cálcio, sendo suas concentrações menores, pois os solos tendem a ser exauridos de magnésio um pouco antes de terem se esgotado minerais mais resistentes de potássio, sódio e cálcio (Buckman \& Brady, 1966; Troeh \& Thompson, 2007). Níveis baixos de fósforo podem afetar no crescimento da videira e reduzir o teor de açúcar do fruto, por estar associado ao metabolismo de açúcares. A melhor forma de manter o fósforo disponível e aumentar a eficiência do adubo, é incorporando-o junto com matéria orgânica seca à superfície do solo. Níveis baixos de cálcio afetam o crescimento dos ramos e raízes. A calagem e o uso de fertilizantes contendo cálcio contribuem para a melhoria no teor deste nutriente no solo (Troeh \& Thompson, 2007). O magnésio é vital para a fotossíntese, pois toda molécula de clorofila contém íons magnésio, níveis baixos do mesmo, contribuem para o efeito da clorose, e os frutos são geralmente reduzidos se comparados

Tabela 2 - Resultados das análises de Matéria Orgânica do Solo (MOS), pH em água e de macronutrientes do solo presentes na área de plantio das cultivares BRS Cora e Niágara Rosada, em diferentes profundidades

\begin{tabular}{|c|c|c|c|c|c|c|c|c|}
\hline $\begin{array}{l}\text { Profundidade } \\
\qquad \mathrm{cm}\end{array}$ & $\begin{array}{c}\text { MOS } \\
\operatorname{dag} \mathrm{Kg}^{-1}\end{array}$ & $\underset{\mathrm{pH} \mathrm{em} \mathrm{H}_{2} \mathrm{O}}{\mathrm{mg} \mathrm{dm}^{-3}}$ & $\begin{array}{l}\text { Fósforo } \\
\mathrm{mg} \mathrm{dm}^{-3}\end{array}$ & $\begin{array}{l}\text { Potássio } \\
\mathrm{mg} \mathrm{dm}^{-3}\end{array}$ & $\begin{array}{l}\text { Enxofre } \\
\mathrm{mg} \mathrm{dm}^{-3}\end{array}$ & $\begin{array}{l}\text { Cálcio } \\
\text { cmol }\end{array}$ & $\begin{array}{l}\text { Magnésio } \\
\text { cmol }\end{array}$ & $\begin{array}{l}\text { Nitrogênio } \\
\mathrm{mg} \mathrm{dm}^{-3}\end{array}$ \\
\hline \multicolumn{9}{|c|}{ BRS Cora } \\
\hline $0-20$ & 2,4 & 5,3 & 6,0 & 91,0 & 8,0 & 1,6 & 0,5 & 0,1 \\
\hline $20-40$ & 2,1 & 5,1 & 3,0 & 72,0 & 23,0 & 0,8 & 0,2 & 0,1 \\
\hline \multicolumn{9}{|c|}{ Niágara Rosada } \\
\hline $0-20$ & 2,2 & 4,8 & 3,0 & 61,0 & 19,0 & 0,5 & 0,2 & 0,1 \\
\hline $20-40$ & 1,9 & 4,7 & 2,0 & 48,0 & 41,0 & 0,3 & 0,1 & 0,1 \\
\hline
\end{tabular}

Tabela 3 - Resultados das análises de micronutrientes do solo presentes na área de plantio das cultivares BRS Cora e Niágara Rosada, em diferentes profundidades

\begin{tabular}{|c|c|c|c|c|c|}
\hline $\begin{array}{l}\text { Profundidade } \\
\mathrm{cm}\end{array}$ & $\begin{array}{c}\text { Ferro } \\
\mathrm{mg} \mathrm{dm}^{-3}\end{array}$ & $\begin{array}{l}\text { Manganês } \\
\mathrm{mg} \mathrm{dm}^{-3}\end{array}$ & $\begin{array}{c}\text { Cobre } \\
\mathrm{mg} \mathrm{dm}^{-3}\end{array}$ & $\begin{array}{c}\text { Zinco } \\
\mathrm{mg} \mathrm{dm}^{-3}\end{array}$ & $\begin{array}{c}\text { Boro } \\
\mathrm{mg} \mathrm{dm}^{-3}\end{array}$ \\
\hline \multicolumn{6}{|c|}{ BRS Cora } \\
\hline $0-20$ & 380,0 & 45,0 & 3,3 & 4,0 & 0,5 \\
\hline $20-40$ & 494,0 & 59,0 & 3,0 & 3,3 & 0,5 \\
\hline \multicolumn{6}{|c|}{ Niágara Rosada } \\
\hline $0-20$ & 141,0 & 7,0 & 0,4 & 0,7 & 0,6 \\
\hline $20-40$ & 144,0 & 4,0 & 0,3 & 0,6 & 0,7 \\
\hline
\end{tabular}


aos normais. Adeficiência de magnésio pode ser corrigida com a adição de calcários e com aplicação de sulfato de magnésio e potássio (Epstein \& Bloom, 2004).

Os teores de potássio encontram-se em concentrações médias (de 60 a $150 \mathrm{mg} \mathrm{dm}^{-3}$ ), com exceção para Niágara Rosada $20 \mathrm{~cm}$ a $40 \mathrm{~cm}$ de profundidade (Tabela 2), no entanto, as baixas concentrações de cálcio e magnésio podem diminuir absorção do potássio pelas plantas (Tecchio et al., 2006). Em relação aos teores de enxofre, o mesmo apresenta concentrações altas (> $\left.10 \mathrm{mg} \mathrm{dm}^{-3}\right)$, exceto para BRS Cora $0 \mathrm{~cm}-20$ $\mathrm{cm}$. Valores elevados de enxofre podem estar associados ao material de origem do solo (rocha mãe). A correção da acidez (calagem) feita na superfície do solo, favorece a movimentação do enxofre para as camadas mais profundas. O enxofre é utilizado em grandes quantidades pelas plantas, que o absorvem como íons de sulfato no solo, sendo parte vital das proteínas, associandose a alguns hormônios vegetais (Osório Filho, 2006). Os resultados indicam altas concentrações de ferro (> $200 \mathrm{mg} \mathrm{dm}^{-3}$ ) nas duas profundidades de BRS Cora e média no solo da Niágara Rosada (31 a $200 \mathrm{mg} \mathrm{dm}^{-3}$ ). Em contrapartida, foram verificadas altas concentrações de Boro $\left(0,61\right.$ a $\left.0,90 \mathrm{mg} \mathrm{dm}^{-3}\right)$ nas duas profundidades de Niágara Rosada e concentrações médias no solo da BRS Cora $\left(0,36\right.$ a $\left.0,60 \mathrm{mg} \mathrm{dm}^{-3}\right)$. Os valores elevados de ferro no solo da BRS Cora podem estar associados a composição mineralógica do solo, pois nestas cultivares o solo apresentou coloração mais escura. Os altos teores de boro podem ser associados à MOS e ao tipo de rocha de origem e seus minerais, como os borosilicatos, encontrados em rochas ígneas e comumente acumulados em rochas sedimentares (Ferreira, 2003). O ferro atua como catalisador na formação da clorofila e para algumas funções em enzimas do sistema respiratório. Valores de $\mathrm{pH}$ entre 4 e 5 tornam o ferro tóxico para as plantas, limitando o seu crescimento. $\mathrm{O}$ excesso de boro, em níveis tóxicos, pode causar desnutrição e diminuir o crescimento das plantas (Troeh \& Thompson, 2007).
Foram verificadas baixas concentrações de manganês $\left(6 \mathrm{a} 11 \mathrm{mg} \mathrm{dm}^{-3}\right)$ para Niágara $0 \mathrm{~cm}-20 \mathrm{~cm}$, muito baixa $\left(<6 \mathrm{mg} \mathrm{dm}^{-3}\right)$ entre $20 \mathrm{~cm}-40 \mathrm{~cm}$, e dentro da média para BRS Cora (12 a $\left.130 \mathrm{mg} \mathrm{dm}^{-3}\right)$. As concentrações de zinco muito baixas $\left(<4,0 \mathrm{mg} \mathrm{dm}^{-3}\right)$ para as duas cultivares, já o cobre encontra-se em concentrações muito baixas $\left(<0,6 \mathrm{mg} \mathrm{dm}^{-3}\right)$ para Niágara Rosada e média em BRS Cora $\left(1,6 \mathrm{a} 20 \mathrm{mg} \mathrm{dm}^{-3}\right)$. A superfície inclinada na área de plantio da Niágara Rosada pode ser um agravante no processo de lixiviação de nutrientes, como o zinco, manganês e cobre. De acordo com Troeh \& Thompson (2007), o manganês lixivia em solos ácidos bem drenados porque a oxidação e a acidez aumentam sua solubilidade. $\mathrm{O} \mathrm{pH}$ ácido do solo também aumenta a mobilidade do cobre dificultando a retenção deste nutriente. Em regiões de clima tropical o zinco pode ser permanentemente deficiente (Sodré et al., 1999). O manganês atua na formação da clorofila e nos sistemas enzimáticos das plantas associados com a respiração. A deficiência pode ocasionar um amarelecimento das folhas. A fertilização feita com sulfato e quelatos de manganês ajudam no aumento do teor deste nutriente no solo (Epstein \& Bloom, 2004). O cobre está envolvido na ativação de várias enzimas das plantas e na formação da clorofila. Níveis baixos deste nutriente afetam no crescimento e pode ocasionar o amarelecimento das folhas nos ramos mais novos. O sulfato de cobre é o fertilizante mais utilizado para a correção, sendo eficaz em solos ácidos (Troeh \& Thompson, 2007). O zinco é importante no metabolismo de proteínas das plantas e sua falta pode ocasionar o acúmulo de outros nutrientes, impedindo a formação de substâncias orgânicas. O sulfato de zinco é bastante utilizado para suprir este micronutriente no solo (Primavesi, 2002).

Os resultados das análises microbiológicas podem ser observados na Tabela 4 . O crescimento de cada micro-organismo diminuiu de acordo com o aumento da diluição, como esperado. Com a contagem de unidades formadoras de colônias e densidade dos grupos de micro-organismos, foi observada maior densidade

Tabela 4 - População microbiana do solo nas áreas de cultivo de BRS Cora e Niágara Rosada, nas profundidades de $0 \mathrm{~cm}-20 \mathrm{~cm}$

\begin{tabular}{lcc}
\hline Densidade populacional/g de solo & BRS Cora & Niágara Rosada \\
\hline Bactérias (UFC x $10^{4} \mathrm{~g}^{-1}$ ) & 3,40 & 3,07 \\
Actinomicetos (UFC x $10^{5} \mathrm{~g}^{-1}$ ) & 1,99 & 2,21 \\
Fungos (UFC x $10^{5} \mathrm{~g}^{-1}$ ) & 4,73 & 6,63 \\
\hline
\end{tabular}


populacional de fungos e actinomicetos, na ordem de $10^{5}$ células por grama de solo, quando comparado com a quantidade de bactérias, que apresentou número de células na ordem de $10^{4}$ a cada grama de solo. Os resultados para ambas as cultivares foram compatíveis com os resultados das análises de $\mathrm{pH}$ dos solos, pois o crescimento de fungos foi maior que os demais microrganismos, devido ao favorecimento da acidez do solo, como pode ser observado também nos trabalhos realizados por Souto et al. (2008), Rech et al. (2013); e Olajire-Ajayi et al. (2015). No entanto, Rech et al. (2013) destacam que as técnicas e meios de cultura empregados podem levar a variações nos resultados.

\section{CONCLUSÕES}

Arenoso e levemente ácido, o solo das culturas de BRS Cora e Niágara Rosada tende a um elevado grau de permeabilidade, sendo mais suscetíveis ao processo de lixiviação causado pela água pluvial e pela irrigação, contribuindo para valores baixos da maioria dos nutrientes do solo avaliados.

A análise microbiológica do solo revelou que os grupos dos fungos e actinomicetos apresentam crescimento favorecido pelas condições de $\mathrm{pH}$ do solo.

As avaliações quanto aos teores de macro e micronutrientes do solo indicaram deficiências e excessos desses nutrientes essenciais às plantas, decorrentes da falta de conhecimento do produtor sobre processos de manejo do solo, e que devem ser considerados para adequada correção do solo, uma vez que podem influenciar qualitativamente e quantitativamente na produção.

\section{LITERATURA CITADA}

BARROTI, G.; NAHAS, E. População microbiana total e solubilizadora de fosfato em solo submetido a diferentes sistemas de cultivo. Pesquisa Agropecuária Brasileira, v.35, n.10, p.2043-2050, 2000.

\section{BERTONI, J; LOMBARDI NETO, F. Conservação} do solo. 4.ed., São Paulo: Ícone; 1999. 355p.

BORTOLON, L.; GIANELLO, C.; SCHLINDWEIN, J.A. Disponibilidade de potássio para as plantas em solos do sul do brasil estimada por métodos multi elementares. Revista Brasileira de Ciência do Solo, v.34, n.5, p.1753-1761, 2010.
BUCKMAN, H.O.; BRADY, N.C. Natureza e propriedades dos solos. 1.ed. Rio de Janeiro: Freitas Bastos; 1966. 590p.

CAMARGO, A.O.; MONIZ, A.C.; JORGE, J.A. et al. 1.ed. Métodos de análise química, mineralógica e física de solos do Instituto Agronômico de Campinas. Campinas: Instituto Agronômico; 2009. 77p.

(Boletim técnico, 106, Edição revista e atualizada). In: http://www.iac.br/publicacoes/

publicacoes_online/pdf/BT_106.pdf (acessado em 15 de Março de 2017).

CAMARGO, U.A.; TONIETTO, J.; HOFFMANN, A. Progressos na viticultura brasileira. Revista Brasileira de Fruticultura, v.33, n.spe, p.144-149, 2011.

CHAVARRIA, G.; BERGAMASCHI, H.; SILVA, L.C. et al. Relações hídricas, rendimento e compostos fenólicos de uvas Cabernet Sauvignon em três tipos de solo. Bragantia, v.70, n.3, p.481-487, 2011.

CORRÊA, M.P. Dicionário das plantas úteis do Brasil e das exóticas cultivadas. v.6. Ministério da Agricultura: Instituto Brasileiro de Desenvolvimento Florestal, 1984. 4329p.

EPSTEIN, E.; BLOOM, A. Nutrição mineral das plantas: princípios e perspectivas. 1.ed. Londrina: Editora Planta, 2004. 403p.

FERREIRA, G.B. Dinâmica das frações de micronutrientes catiônicos e esgotamento de formas disponíveis de boro, cobre, ferro, manganês e zinco, em solos de Minas Gerais. Tese (Doutorado em Solos e Nutrição de Plantas). Viçosa, MG: UFV, 2003. 169p.

IBGE - Instituto Brasileiro de Geografia e Estatística. Levantamento Sistemático da Produção Agrícola - janeiro 2017. Brasília: IBGE (2017) In: https://sidra.ibge.gov.br/ home/lspa/brasil (acessado em 28 de Janeiro de 2017).

LEMOS, R.C. de. Manual de descrição e coleta de solo no campo. 4.ed. Viçosa: Sociedade Brasileira de Ciência do Solo, 2002. 83p. 
LUCHESE, E.B.; FAVERO, L.O.B.; LENZI, E. Fundamentos da química do solo: teoria e prática. 1.ed. Rio de Janeiro: Freitas Bastos, 2002. 159p.

MACÊDO, J.A.B. Métodos laboratoriais de análises físico-químicas e microbiológicas. 2.ed. Belo Horizonte: Macêdo, 2003. 450p.

MIELE, A.; FLORES, C.A.; ALBA, J.M.F. et al. Efeito do tipo de solo nos compostos fenólicos e na atividade antioxidante do vinho. Revista Brasileira de Viticultura e Enologia, v.6, n.3, p.40-47, 2014.

MOREIRA, F.M.S.; SIQUEIRA, J.O.

Microbiologia e bioquímica do solo. 2.ed. Lavras: UFLA, 2002. 626p.

OLAJIRE-AJAYI, B.L.; DADA, O.V.; WAHAB, O.M. et al. Effects of fertilizers on soil's microbial growth and populations: a review. American Journal of Engineering Research (AJER), v.4, n.7, p.52-61, 2015.

OSÓRIO FILHO, B.D. Dinâmica de enxofre no sistema solo e resposta das culturas à adubação sulfatada. Dissertação (Mestrado em Ciência do Solo). Santa Maria: UFSM, 2006. 75p. In: http:// w3.ufsm.br/ppgcs/images/Dissertacoes/BENJAMINDIAS-OSORIO-FILHO.pdf (acessado em 15 Março de 2017).

OSÓRIO FILHO, B.D.; RHEINHEIMER, D.S.; SILVA, L.S. et al. Deposição do enxofre atmosférico no solo pelas precipitações pluviais e respostas de culturas à adubação sulfatada em sistema plantio direto. Ciência Rural, v.37, n.3, p.712-719, 2007.

PADMAVATHY, A.; POYYAMOLI, G. Effects of Conventional and Organic Management Strategies on soil quality in biodiversity agricultural Fields of Bahour, Puducherry, India. AmericanEurasian Journal of Agricultural \& Environmental Science, v.10, n.4, p.644-652, 2011.

PAVAN, M.A.; BLOCH, M.F.M.; ZEMPULSKI, H.C. et al. Manual de análise química de solo e controle de qualidade. Londrina, Instituto Agronômico do Paraná, 1992. 40p.
PRIMAVESI, A. Manejo ecológico do solo: a agricultura em regiões tropicais. 1.ed. São Paulo: Nobel, 2002. 541p.

RAIJ, B. van; ANDRADE, J.C.; CANTARELLA, H. et al. Análise química para avaliação da fertilidade de solos tropicais. Campinas: Instituto Agronômico de Campinas, 2001.284p.

RECH, M.; PANSERA, M.R.; SARTORI, V.C. et al. Microbiota do solo em vinhedos agroecológico e convencional e sob vegetação nativa em Caxias do Sul, RS. Revista Brasileira de Agroecologia, v.8, n.3, p.141-151, 2013.

REGANOLD, J.P.; GLOVER, J.D.; ANDREWS, P.K. et al. Sustainability of three apple production systems. Nature, v.410, n.19, p.926-930, 2001.

ROBERTO, S.R.; SATO, A.J.; BRENNER, E.A. et al. Fenologia e soma térmica (graus-dia) para a videira 'Isabel' (Vitis labrusca) cultivada no Noroeste do Paraná. Semina: Ciências Agrárias, v.25, n.4, p.273-280, 2004.

RODRIGHERO, D.M.B.; BARTH, G.; CAIRES, E.F Aplicação superficial de calcário com diferentes teores de magnésio e granulometrias em sistema plantio. Revista Brasileira de Ciência do Solo, v.39, n.6, p.1723-1736, 2015.

ROSSI, C.Q.; PEREIRA, M.G.; AQUINO, A.M. et al. Atributos químicos e físicos de solo cultivado com oleráceas em microbacia hidrográfica, após desastre ambiental. Revista Brasileira de Ciência do Solo, v.39, n.6, p.1764-1775, 2015.

SAMPAIO, T.F.; FERNANDES, D.M.; GUERRINI, I.A. et al. Comparação entre Métodos para Determinação de Carbono Orgânico em Amostras de Solo Mensuradas por Volume ou Massa.

Revista Brasileira de Ciência do Solo, v.36, n.2, p.517-523, 2012.

SEAG. Plano Estratégico de

Desenvolvimento da Agricultura: novo PEDEAG 2007-2025 / Secretaria de

Estado da Agricultura, Abastecimento, Aquicultura e Pesca. Vitória-ES: SEAG, 2008. 284p. In: http://www.es-acao.org.br/_midias/pdf/ NovoPEDEAG.PDF (acessado em 29 de Março de 2016) 
SILVA, N.D.; JUNQUEIRA, V.C.A.; SILVEIRA, N.F.A. Manual de métodos de análise microbiológica de alimentos. 2.ed. São Paulo: Livraria Varela, 2001.317p.

SKOOG, D.A.; HOLLER, F.J.; NIEMAN, T.A. Princípios de análise instrumental. 5.ed. Porto Alegre: Bookman, 2002. 836p.

SODRÉ, F.F.; COSTA, A.C.S.; LENZI, E. Adsorção de cobre em solos tropicais com diferentes mineralogias. Acta Scientiarum, v.21, n.3, p.483-489, 1999.

SOUTO, P.C.; SOUTO, J.S.; MIRANDA, J.R.P. et al. Comunidade microbiana e mesofauna edáficas em solo sob caatinga no semi-árido da Paraíba.

Revista Brasileira de Ciência do Solo, v.32, n.1, p.151-160, 2008.

SOUZA, E.C.; UCHÔA-THOMAZ.; A.M.A.; CARIOCA, J.O.B. et al. Chemical composition and bioactive compounds of grape pomace (Vitis vinifera L.), Benitaka variety, grown in the semiarid region of Northeast Brazil. Food Science and Technology, v.34, n.1, p.135142, 2014.
TECCHIO, M.A.; PAIOLI-PIRES, E.J.; TERRA, M.M. et al. Correlação entre a produtividade e os resultados de análise foliar e de solo em vinhedos de Niagara Rosada. Ciência e Agrotecnologia, v.30, n.6, p.1056-1064, 2006.

TROEH, F.R.; THOMPSON, L.M. Solos e fertilidade dos solos. 6.ed. São Paulo: Andrei, 2007. 718p.

TOMÉ JR, J.B. Manual para interpretação de análise de solo. 1.ed. Rio Grande do Sul: Agropecuária, 1997. 247p.

VALLADARES, G.S.; PEREIRA, M.G.; SOUZA, J.M.P.F. et al. Comparação entre os teores de nutrientes extraídos por três métodos em amostras de solos do Rio de Janeiro. Revista

Brasileira de Agrociência, v.7, n. 2, p.137141, 2001.

WUTKE, E.B.; CARVALHO, C.R.L.; COSTA, F. et al. Qualidade de frutos de videira 'Niagara Rosada' em cultivo intercalar com gramínea e leguminosas. Revista Brasileira de Fruticultura, v.26, n.1, p.92-96. 2004.

Recebido para publicação em 17/3/2017 e aprovado em 28/5/2017. 